\title{
International Journal of \\ Relationship of attitude with socio-economic status on judokas
}

\section{DEEPAK DHAKA}

Received : 11.06.2014; Accepted : 26.09.2014

Author for correspondence : DEEPAK DHAKA

Bhagat Phool Singh Mahila

Vishwavidayalaya, Khanpur Kalan, SONEPAT (HARYANA) INDIA

Email: deepakjudoka@gmail.com

\section{- ABSTRACT}

Due to increasing discrepancies between the social status of individuals and unrest in life, their performance and motivation level might be affected drastically. Attitude level may also vary for different groups of SES. To control the behavior and enhance performance of an individual, it is crucial to study the various factors those may possibly influence their achievements. The present paper focuses on the Socio-economic status of Judokas and their relationship with the attitude. The paper further describes that how the given factors of attitude i.e. Social change, Social distance, Liberalism, Nationalism, Social revolutionism and Untouchability are related to the different Socio-economic classes mainly with Low SES and High SES. As a consequence of the breach between Low SES and High SES, attitude level could also be different for these two groups. Thus the present study possibly will help in identifying such variations at both individual and societal levels furthermore their relationship with the attitude so that necessary measures can be taken to cultivate the efforts of judokas in a right direction.

- Key Words : Attitude, Low SES, High SES, Social change, Social distance, Liberalism, Nationalism, Social revolutionism and Untouchability

- How to cite this paper : Dhaka, Deepak (2014). Relationship of attitude with socio-economic status on judokas Internat. J. Phy. Edu., 7 (2) : 81-85. 